Research Article

\section{Biodegradation of gold and platinum implants in rats studied by electron microscopy}

\author{
Hendrik Kosslick ${ }^{1}$, Hermann Sauer ${ }^{2}$, Tino Just ${ }^{3}$, Ursula Vick ${ }^{4}$, \\ Gerhard Fulda ${ }^{5}$ and Ludwig Jonas ${ }^{5 *}$ \\ 'Institute of Chemistry, University of Rostock, Albert-Einstein-Str. 3a, D-18051 Rostock, Germany
} ${ }^{2}$ Department of Inorganic Chemistry, Fritz-Haber-Institute of the Max-Planck-Society (MPG), Faraday Weg, Berlin, Germany ${ }^{3}$ Department of Otorhinolaryngology, Head and Neck Surgery, KMG Klinikum Güstrow, Friedrich Trendelenburg-Allee 1, 18273 Güstrow, Germany

${ }^{4} \mathrm{Clinic}$ and Policlinic for Ear, Nose and Throat Disease, Faculty of Medicine, University of Rostock, Doberaner Str, Rostock, Germany

${ }^{5}$ Department of Pathology, Electron Microscopic Center, Faculty of Medicine, University of Rostock, Strempel Str, Rostock, Germany

\section{Abstract}

\section{Graphical abstract}

Biodegradation of implanted gold in human tissue. TEM images reveal markedly biodegradation of implanted gold and re-crystallization of dissolved gold as nanoparticle of different size, shape and crystallinity. Highly crystalline icosahedral Au nanoparticle and the corresponding power spectrum are shown on top.

Background: Despite the importance of biodegradation for the durability of metal prosthesis and the widely use of gold implants, there exist a lack of knowledge regarding the stability of pure gold in tissue.

Methods: We studied biodegradation of grids of pure gold, nickel, and copper as well as middle ear prosthesis of gold, platinum or titanium. Metals were implanted into rat skin and humans. Dissolution and re-crystallization process of the metals was analysed using SEM, TEM, power spectra as well as elemental analysis by EDX and EELS/ESI.

Results: Biodegradation of gold was detected, presumably by solving and re-precipitation of gold around implants. Gold cluster, nanoparticles, and mesostructures were detected, formed by dissolution and re-crystallization process. This process results into a migration of gold into the farer off tissue. Cellular filaments as biomolecular templates facilitate the formation of mesostructures. Loss of function of middle ear prosthesis by biodegradation is caused by chronic inflammation and fibrosis. Indeed, similar processes were detected with platinum, but in a very lower level.

Conclusion: Noble metal implants undergo biodegradation in oxidative environment in tissue. The dissolution - recrystallization process can be explained by enzyme catalysed redox processes comprising reactive oxygen species and reduction agents as ascorbic acid present in cells and body tissue. Enymes like myeloperoxidase inside lysosomes of inflammatory cells produce hypochloride ions and $\mathrm{H}_{2} \mathrm{O}_{2}$ which can dissolve the gold.

General significance: The crucial role of the specific chemical environments of gold implants in tissue for their chemical stability and durability of function has been demonstrated. Due to widely use and importance of gold implants, this finding is of general interes.

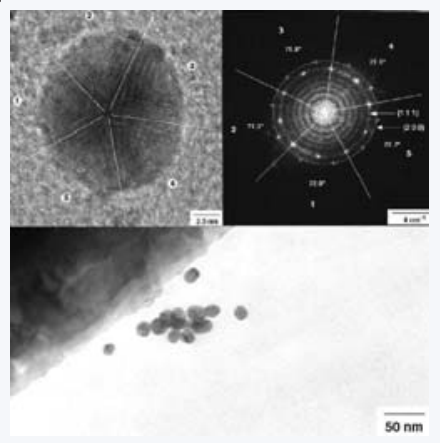

\section{More Information}

*Address for Correspondence: Ludwig Jonas, Electron Microscopic Center, Department of Pathology, Medical Faculty, University of Rostock, D-18055 Rostock, Germany, Strempel Str 14, Fax: +49 381494 5802, Tel: +49 381494 5850; Email: ludwig.jonas@gmx.de

Submitted: 07 November 2019

Approved: 26 November 2019

Published: 27 November 2019

How to cite this article: Kosslick $\mathrm{H}$, Sauer $\mathrm{H}$, Just T, Vick U, Fulda G, et al. Biodegradation of gold and platinum implants in rats studied by electron microscopy. Int J Phys Res Appl. 2019; 2: 041-048.

DOI: dx.doi.org/10.29328/journal.ijpra.1001014

Copyright: () 2019 Kosslick H, et al. This is an open access article distributed under the Creative Commons Attribution License, which permits unrestricted use, distribution, and reproduction in any medium, provided the original work is properly cited.

Keywords: Gold; Platinum; Biodegradation; Implants; Au nanoparticle; Recrystallization; Self-assembly

\section{Check for updates}




\section{Introduction}

Biodegradation of metallic implants and biomaterials was observed mostly of non-noble metals, such as titanium and stainless steel [1,2-13]. Sometimes, a so-called metallose is visible in the surrounding tissue after long-term insertion of titanium plates for osteosynthesis or titanium staffs for therapy of scoliosis of the back bone. Macroscopically, metallose visible as a darkening of the skin [14]. Metallose of tissue is related to a fine spread distribution of small particles of metals or metal oxides [1,12-16]. The corresponding areas show a black to grey-bluish colour, even if the implanted metals were of silver or gold. In the past, we reported about a young lady with a tattoo on her neck skin after a flush over by lightning stroke which caused a partial evaporation of her golden ornamental chain [1]. We detected gold particles in her skin with sizes of $5 \mathrm{~nm}$ to $30 \mu \mathrm{m}$, and up to $2 \mathrm{~mm}$ deep in the subcutaneous tissue. They were mostly incorporated inside of phagocytic histiocytes, fibroblasts and foreign multinucleated giant cells as shown by light microscopy as well as Transmission Electron Microscopy (TEM) and Scanning Electron Microscopy (SEM). The partial crystalline nature of these gold deposits was proven by high power TEM electron diffraction. In the case of the lady with the gold tattoo, interestingly, a re-inspection of the material after one year of deposition gave indications for the occurrence of a possible biodegradation and re-crystallization of the gold alloy from the jewellery chain.

Based on these preliminary findings, here, we study the possible biodegradation of pure gold implants in the rat neck skin after two months of insertion, as shown by Danscher, et al. [14]. Furthermore, we compare the experimental biodegradation of gold, nickel and copper grids as well as gold, platinum and titanium middle ear prostheses in rats with that of middle ear prostheses after long-term implantation into patients. We will demonstrate that even the noble pure gold, which is stable for long time in use for teeth implants in the mouth can suffer a biodegradation in body tissue environment. Additionally, we present results about the crystalline nature of formed gold clusters. A hypothesis of the formation of these gold nanoparticles by a dissolution and re-crystallization process is given. These processes lead to a wide spread of gold particles into the tissue around the implant and in part far from the location of the gold implant causing inflammation and fibrosis.

\section{Material and Methods}

\section{Patient material}

As already described [1], we studied a skin biopsy of a 24 years old lady, who had a tattoo around her neck after a lightning stroke and flush over with partial evaporation of her ornamental chain. As analysed by Energy Dispersive X Ray Diffraction (EDX), Electron Energy Loss Spectroscopy (EELS) and Atomic Absorption Spectroscopy (AAS), this gold chain was an alloy of $70 \%$ gold, $20 \%$ silver and $10 \%$ copper. The original gold chain was lost at the accident, unfortunately. The biopsy was taken one year after tattooing. The tissue was fixed in $4 \%$ glutaraldehyde in phosphate buffered saline (PBS) for $1 \mathrm{~h}$, washed in $\mathrm{PBS}$, post fixed in $1 \% \mathrm{OsO}_{4}$, dehydrated in acetone and embedded in epoxy resin Araldite (Buchs, Swiss).

\section{Gold samples}

As a test material for gold biodegradation, we used pure gold grids, normally used for preparation in the electron microscopy (200 mesh, Plano, Germany). The purity of grids was estimated as $100 \%$ gold by EDX (KEVEX) in a SEM (DSM 960 A, Zeiss, Germany). For comparison, copper and nickel grids were used (200 mash, Plano, Germany). Furthermore, middle ear prostheses for stapedioplasty and therapy of partial deafness of gold, platinum or titanium (Smith and Nephew Inc. Barlett, TN, USA) were implanted for comparison of biodegradation under the neck skin of rats. More recently, we used prostheses of the company Kunz (Heinz Kunz GmbH Medizintechnik Dußlingen, Germany) for implantation in patients. Additionally, we studied explanted prostheses and the surrounding tissue in TEM and SEM.

\section{Experimental animals}

Twenty white male rats of an inbred strain (LEW 1W Strain Karlsburg, Germany) with a start body weight of $200 \mathrm{~g}$ were used for implantation experiments. The animals were bred in the animal house of the Department of Pathology, University of Rostock, and fed with rat standard diet and water ad libitum.

\section{Implantation and explantation}

The rats were anaesthetised by a combination of Ketanest (Parke-Davis, Berlin, Germany) and Rompun (Bayer, Leverkusen, Germany). The gold, nickel, and copper grids or the gold, platinum, and titanium middle ear prostheses were placed into a cut of skin behind the right ear into the subcutis. The cut was closed by two or three stitches with an operation needle and suture material. Two months after implantation, the test materials were explanted from the tissue by a second operation. The middle ear prostheses of patients were explanted after failure of function by an operation under anaesthesia in the Clinic and Policlinic for Ear, Nose and Throat Disease of the University of Rostock, Germany. Out of 42 explants of patients, fife prostheses with the surrounding tissue were studied by electron microscopy.

\section{Preparation of tissue and ultrathin sections}

The removed grids or prostheses with the surrounding connective tissue were fixed in $4 \%$ glutaraldehyde in PBS for one hour, washed in the same buffer and post fixed in 1 $\% \mathrm{OsO}_{4}$ for $1 \mathrm{~h}$. The tissue with the included metal artefacts was dehydrated in a graded series of acetone and embedded in epoxy resin Araldite (Buchs, Switzerland). Semithin and ultrathin sections were prepared with an ultramicrotome Ultracut SWS (Leica) using a diamond knife (Diatome, Biel, Switzerland). Semithin sections (0.5-1.5 $\mu \mathrm{m})$ were used for light microscopic studies in the polarizing mode after toluidine blue staining. 


\section{Electron microscopic studies}

Transmission electron microscopy: Ultrathin sections were studied after contrastation with uranyl acetate and lead citrate or without contrastation in an $80 \mathrm{kV}$ TEM (Zeiss EM 902 A), $120 \mathrm{kV}$ TEM (Zeiss Libra 120) or a $200 \mathrm{kV}$ TEM (Philips CM 200 FEG). High resolution TEM images were taken with a Gatan SlowScan Camera. Power spectra of the images were calculated with Gatan Digital Micrograph software.

Scanning electron microscopy: Middle ear prosthesis for stapedioplasty and therapy of partial deafness were studies before and after implantation/explantation in an SEM DSM 960 A (Zeiss, Germany).

\section{Elemental analysis}

To estimate the elemental composition of implants or to demonstrate elemental distribution, we used analytical electron microscopy. In EM 902 A we used EELS with a prismatic filter, electrostatic mirror type Castaing/Ottismeyer, a CCD camera (Proscan Germany), a Pentium computer with EFTEM software package (Olympus SIS, Muenster, Germany). In Libra 120 we used EELS analysis with an omega filter and a 2K CCD camera (Proscan Germany) or the EDX system (EDAX). At the SEM DSM $960 \mathrm{~A}$, we analysed the elemental composition by EDX system (KEVEX).

\section{Results}

\section{Biodegradation investigation}

Figure 1 shows gold deposites in a skin tissue macrophage (histiocyte) after one year of a flush over and partial evaporation of an ornamental chain at the neck of a young lady, as published in [1]. Besides granular, globular gold particles, longitudinal stick or bar-like structures and tanglelike tracks are observed. Detailed TEM inspection showed that the stick or bar-like structure are hollow and resemble gold nanotubes. The shape of these diverse structures remembers of self-assembled nanostructures. The formation of such wellshaped and organized superstructures of nanoparticles seems to be unlikely the direct result of the flush over.

Because the evaporated gold ornamental chain of the lady was an alloy of gold, silver, and copper we studied the process of possible biodegradation on pure gold grids after implantation under the neck skin of rats. To prove the hypothesis that the observed pattern of nanoparticle assemblies did not arose primarily under evaporation by the flash over in the skin, but occur by re-crystallization and re-arrangement of gold atoms within the period of storage of gold within the cells under the influence of oxidation and reduction processes, we decided to implant pure gold grids (instead of alloys). After two months of depositing, the surrounded tissue of the explanted grids shows amorphous gold clusters (globules) of about 5 to 10 $\mathrm{nm}$ size (Figure 2). They are located close to the metallic surface, which is x-ray amorphous. Besides, gold precipitates could also be detected in larger distances to the gold grid in the matrix of the connective tissue. Gold precipitates are accumulated inside of fibroblasts and histiocytes. Intracellular, the gold nanoparticles are accumulated by phagocytosis inside lysosomes and residual bodies (Figure 3). Whereas the extra cellular precipitates and gold clusters are mostly of globular shape, the intracellular gold accumulation is often of elongated form, comma-like or pipe-shaped. This observation might indicate already an influence of bio-templating on particle shape inside cells.

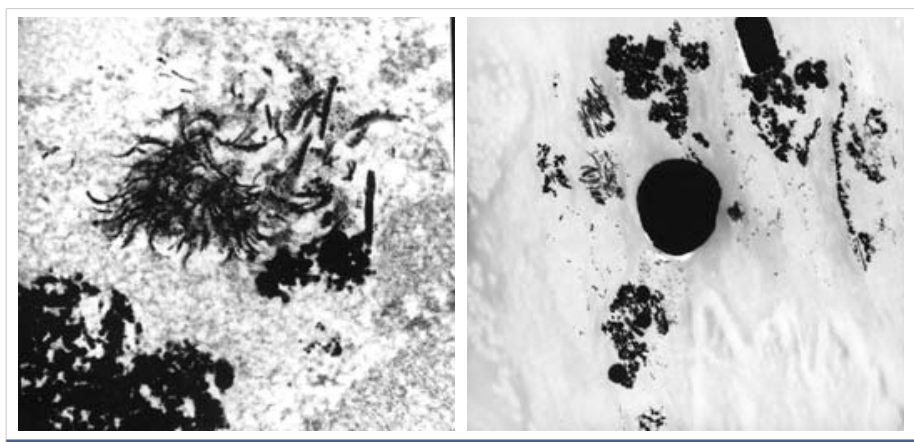

Figure 1: TEM images gold deposits in a skin tissue macrophage (histiocyte) after one year of a flush over and particular evaporation of an ornamental chain at the neck of a young lady. Globular gold particles of different size $(5 \mu \mathrm{m}-5 \mathrm{~nm})$ and barlike structures and tange-like tracks.

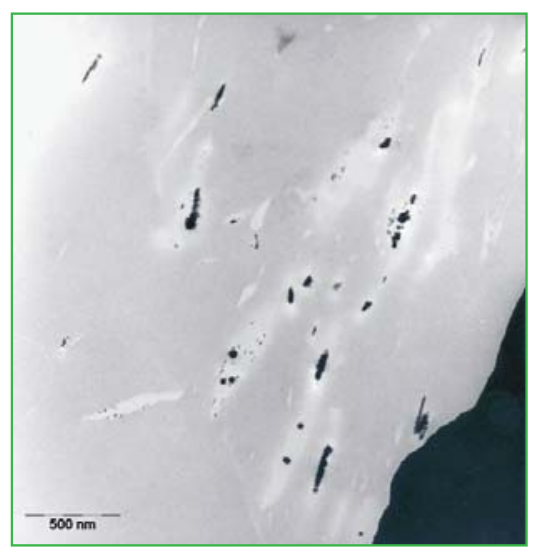

Figure 2: TEM image of the surrounding tissue of an explanted gold grid with gold clusters and gold tracks in the neighbourhood of the implant.

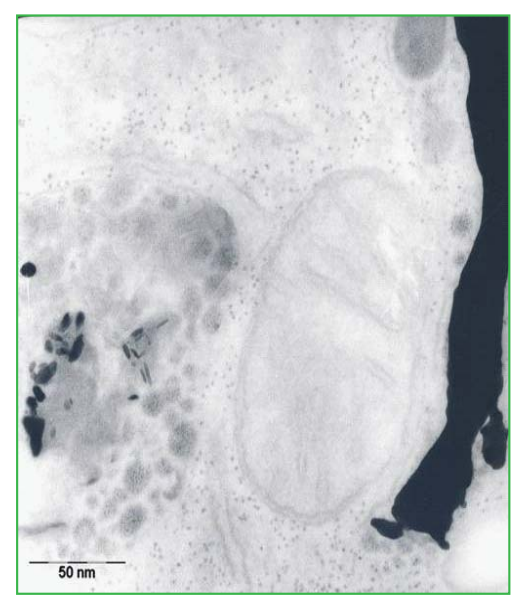

Figure 3: Gold accumulation by intracellular precipitation in a tissue macrophage (histiocyte) inside lysosomes and residual bodies; granular, globular, and elongated forms, comma-like or pipe-shaped structures. 
For comparison non-noble copper and nickel grids were implanted into two rats. After two months, the implants were explanted. Whereas the copper grid was totally corroded and resolved, the nickel grid was only partial degraded. The tissue around the implants was macroscopically discoloured and darkened. In TEM we found numerous fibroblasts and histiocytes, which were full of lysosomes and residual bodies with accumulation of heavy metals. In semi thin sections, we observed numerous mast cells in close connection to the nickel accumulated phagocytes and fibroblasts. After toluidine blue staining of semi thin sections, the histamine producing and storing mast cells were well visible as metachromatic red coloured species as an indication of the allergic reaction against nickel implant (pictures with nickel and copper grids are not shown here).

In parallel, we investigated middle ear prostheses for stapedioplasty, consisting of gold, platinum or titanium. Four of such filigree gold prostheses and one platinum prosthesis are shown in figure 4. The observed biodegradation of these gold prostheses was comparable to that of the gold grids. The accumulation of gold clusters in the connective tissue matrix and phagocytes depends on the period of application. Some implants operated well for more than ten years. The accumulation of gold around the implants increases with the duration of use. The loss of function of prostheses was monitored for different metal species. (Clinical data, not presented here). The gold prostheses seem to have a shorter durability than titanium or platinum ones. We concluded that faster biodegradation could induce an earlier and stronger local chronic inflammation leading to a loss of function.

As found with implanted gold grids, the biodegradation of gold prostheses was visible in TEM. The surrounding tissue and the connective matrix contained precipitates of gold. There was detectable a gradient of precipitated or accumulated gold particle from the metallic surface into the surrounding tissue. With increasing application time in tissue, gold precipitates are more far displaced from the origin. Compared to titanium and platinum, the biodegradation of gold implants was stronger. Interestingly, the biodegradation of titanium prostheses was low. However, we were able to detect also a biodegradation of the noble platinum prostheses. The material purity of the platinum prosthesis has been checked by EDX (Figure 5). The EDX spectrum shows eight characteristic signals of platinum, those confirms the high purity of the material. Other elements could not be detected by EDX.

This high purity platinum prosthesis was implanted into one rat for two months. Again after two months, the surrounding tissue of the platinum prosthesis showed in TEM very few electron dense precipitates in the connective matrix and some granules, accumulated inside lysosomes and residual bodies of histiocytes and fibroblasts as a sign of phagocytosis of those precipitates. They are darker in the element specific imaging (ESI) (Figure 6). In addition, EELS spectra of the implant surrounding tissue have been recorded.

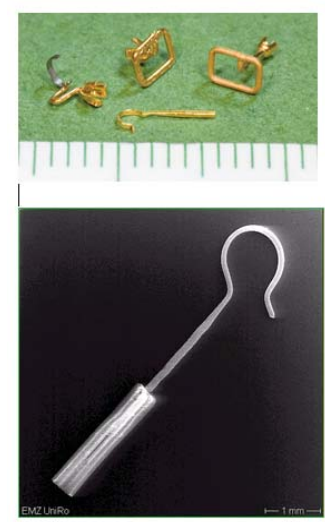

Figure 4: Light microscopic image gold middle ear prostheses (top) and SEM image of a platinum middle ear prosthesis with a Teflon shaft (bottom) before implantation.

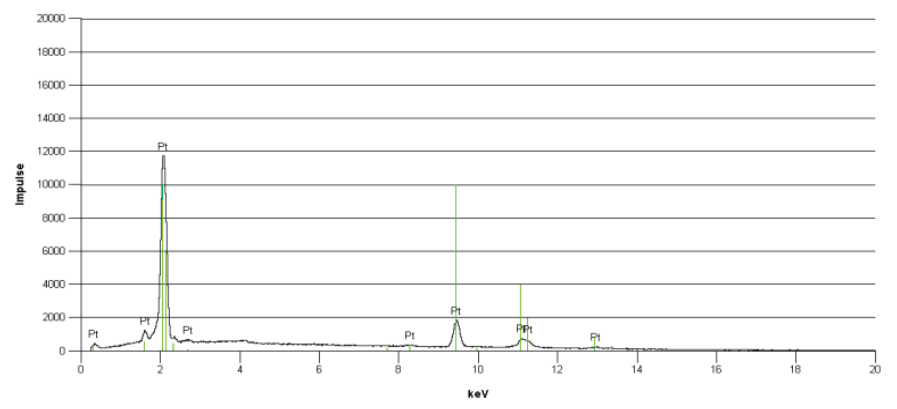

Figure 5: EDX spectrum of the platinum prosthesis (Fig.4) showing clearly 8 platinum specific peaks.
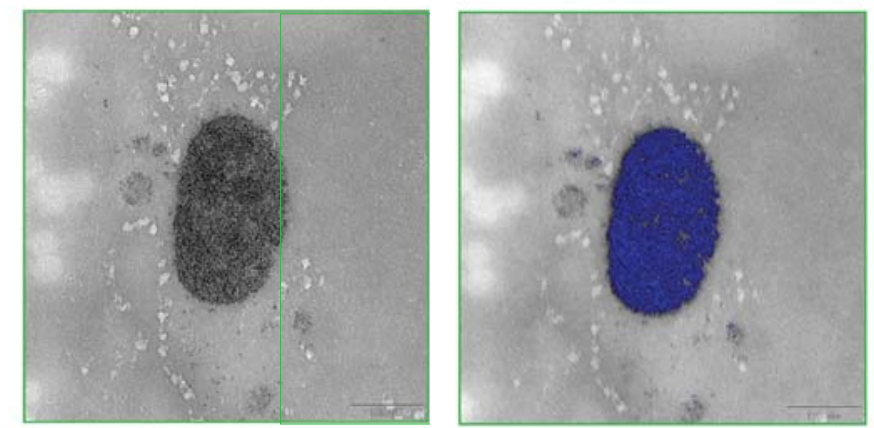

Figure 6: TEM image of electron dense precipitates in the connective matrix and accumulation inside lysosomes and residual bodies of a histiocyte (left) and element specific imaging; ESI, of platinum signals shown in blue after EELS (right).

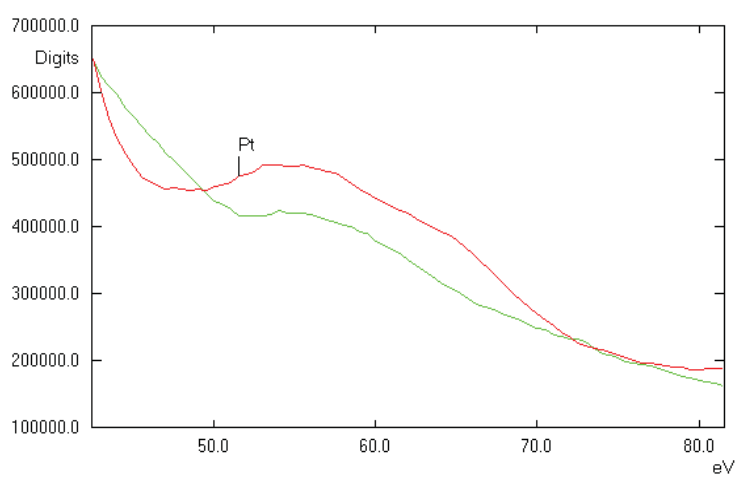

Figure 7: EELS spectrum of electron dense material inside a lysosome (green) showing the presence of platinum deposits. For comparison, the EELS of Pt standard is shown (red). 
The appearance of the platinum specific signals in the EELS spectra confirms dissolution and re-precipitation of platinum from the implant (Figure 7). Hence, biodegradation of noble metals in the tissue is not limited to gold. However, the degree of biodegradation of platinum is much lower compared to gold. The most stable metal implant was titanium. The formation of a stable oxidized surface layer protects the titanium against further chemical attack. Some of the titanium prostheses were nitrified at the surface by the company for a better chemical resistance.

\section{High resolution TEM investigation of nanoparticle}

The metal cluster formed by biodegradation of gold grids were studied in a $200 \mathrm{kV}$ TEM. Ultrathin cuts of the gold grids or middle ear prostheses were possibly by using a diamond knife. Such very thin sections are transmitted by the $200 \mathrm{kV}$ electron beam and revealed a local ordered arrangement of gold atoms in the polycrystalline gold grids and implant. The short-range order in the crystallites is evidenced by the power spectrum showing only some peaks (Figure 8a-c). The ultrathin microtome cut of the gold grid allowed to image ablated round shaped gold particles even located on the backside of the gold section (Figure 9). The surface microstructure of the bulky gold grid appears rather uneven facilitating chemical attack. A part of the round shaped particles are inter grown. These nanoparticles are polycrystalline with grain sizes of ca. $2.5 \mathrm{~nm}$.

Apart from these round particles, a number of very small gold nanoparticles were observed. The size of these nanoparticles differs from some few $\mathrm{nm}$ to $20 \mathrm{~nm}$. They show different shape and atom packing. Some very small particles are irregularly shaped. Probably, they resemble very early stages of the particle growth like seeds (Figure 10). Others are larger and round shaped. Additionally, a number of wellshaped decahedral-like or icosahedral particles are found (Figure 10). The well resolved power spectrum reveals highly ordered arrangement of the gold in the icosahedra (Figure 11). The icosahedra is the energetic most stable form of a crystalline nanoparticle (Nano crystal).

Power spectra have been recorded for polycrystalline gold and a couple of selected single nanoparticle (Figure 11). They show different pattern confirming the crystalline nature of these particles in contrast to amorphous particles. Well shaped icosahedral crystals show well-resolved and more complex patterns showing the high crystallinity and long-range ordering of gold (Figure 11). For comparison, power spectra of gold cluster have been calculated based on structural data of gold. Indeed, they compare very well with experimental results. These calculations confirm independently, that the observed cluster really consists of pure metallic gold.

\section{Discussion}

The observed migration of gold particles due to dissolution of implanted gold as well as re-precipitation of dissolved gold into body tissues with structural reorganization of the gold
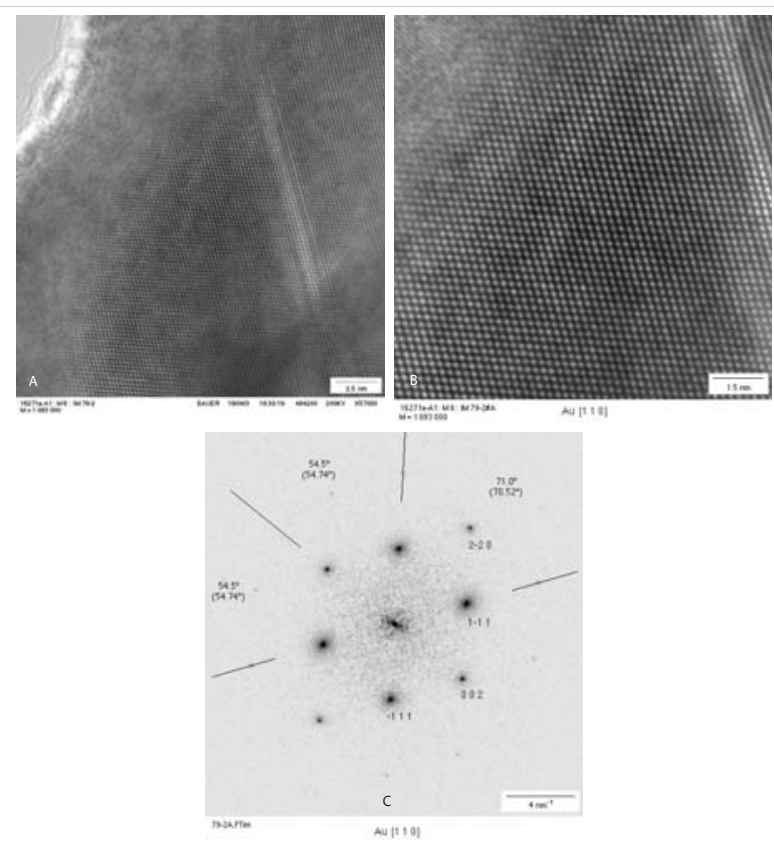

Figure 8: HRTEM image of an ulthrathin section of the implanted polycrystalline gold grid showing surface roughness (a), higher magnification showing

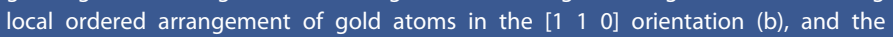
corresponding power spectrum (c).
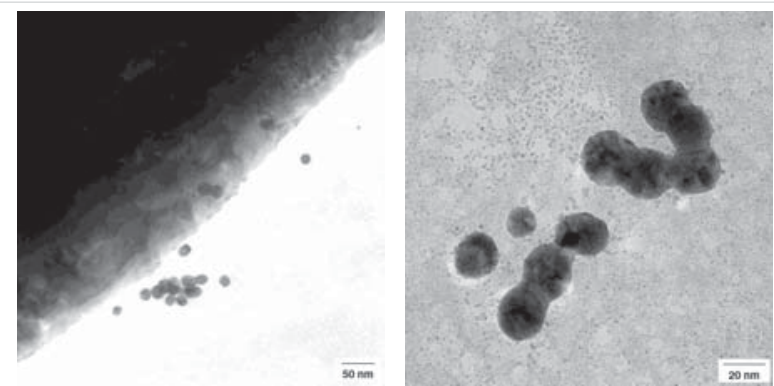

Figure 9: Re-precipitation of gold nanoparticles in the neighbourhood of gold implant by biodegradation of gold. Round shaped nanoparticles of 5- $20 \mathrm{~nm}$ size shown in higher magnifications below in a 200 kV TEM.
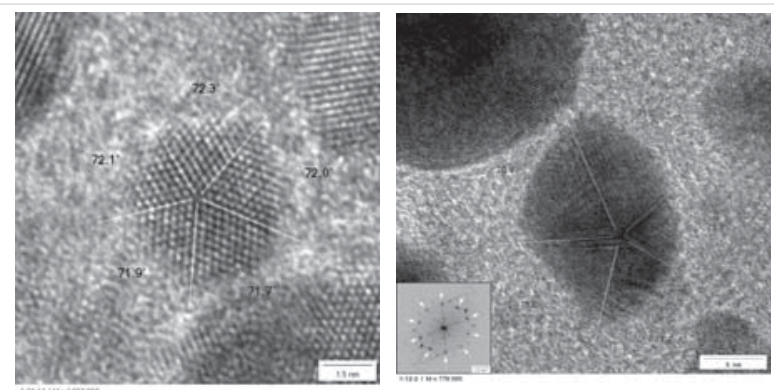

Figure 10: Left: Icosahedral shape of a gold nanoparticle of ca. $5 \mathrm{~nm}$ size in the neighbourhood of round shaped gold particles in $200 \mathrm{kV}$ TEM.

Right TEM image of a decahedral-shaped gold globule with well orientated gold atoms. Inlet shows the power spectrum of the particle. Crystallite size: ca. $15 \mathrm{~nm}$.

particles into a verity of different shapes after comparatively long periods of time is indeed a surprising and unexpected phenomenon [17]. Danscher, et al. was the first, who reported the biodegradation of pure gold grids within animal experiments. Apparently, this finding is in contradiction to the general excepted knowledge of the chemical stability and outstanding noble properties of gold. Pure gold is chemically 

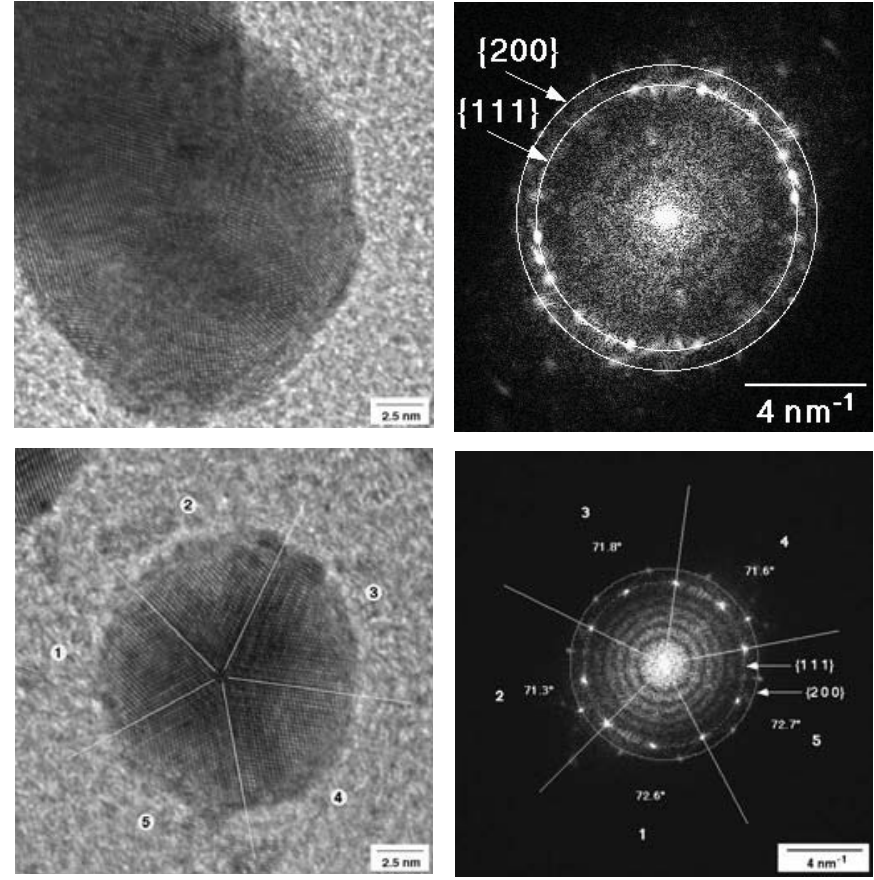

Figure 11: HRTEM images (left) and corresponding power spectra (right) of gold globule with well orientated gold atoms in a less ordered gold globule (top) and of an icosahedra-shaped gold nanoparticle (bottom) showing triangular surface facets in the crystallite.

stable under acidic and alkaline conditions as well as against solvents. So, this metal is used for long-time implantations in the dental apparatus nearly without problems.

However, it must be taken into account, that strong oxidative agents are able to dissolve even the noble gold [18-20]. E.g., Gold is soluble in hypochlorite solution and in oxidative acid, like "aqua regis," a mixture of hydrochloric and nitric acid. This is due to the formation of very reactive nitrosyl chloride [21] and chlorine radicals in "status nascendi". Indeed, the body tissue is also an "aggressive" milieu for implants. Hypochlorite, peroxides or hydroxyl radicals are also present in the tissue provided by peroxidase enzymes in lysosomes and peroxisomes. Additionally, a couple of reactive oxygen species, including the notorious "free radicals" are formed as a by-product of cellular respiration, which can attack the gold. Complexing agents like $\mathrm{Cl}^{-}$anions can also form stable mobile complexes with gold, which are able to migrate through the body fluid by diffusion. Thereby, dissolution of gold is facilitated by shifting the chemical equilibrium [21]. Furthermore, impurities and alloying of gold with copper and silver may decrease the chemical stability. So, corrosion of gold coins and antique jewellery, of course over long periods of time, is well known [22]. Reductive agents in the tissue reduce the dissolved gold again leading to the observed precipitation of gold nanoparticle.

Re-crystallized gold nanoparticles show a lower stability than the bulky gold. The stability of gold particle changes dramatically with the decrease of the particlesizeinto the microand nano -scale. The ratio of surface to bulk atoms increases markedly with lowering particle size. Surface atoms are less strongly bound. They become reactive and undergo readily dissolution by oxidative agents $[23,24]$ and re-crystallize again in the presence of reductive agents like citric acid and ascorbic acid [25] into nanoparticle of different shape and size. It is general known that adsorbing molecules, surfactants and macromolecules, e.g. Oligopeptides, influence the particle size and shape and allow, in desired proportion, a shape and size directed growth of gold nanocrystals and synthesis of nanosized gold sols $[25,26]$. In body tissue re-crystallization of dissolved gold or gold nanoparticles into new shaped structures occurs in the presence of different reductive agents and surfactants, biomolecules, micelles, vesicle and surfaces like bio-membranes and related structures [27-30] explaining the variety of formed particle and structures. As nanoparticles are metastable, the dissolution and recrystallization or reprecipitation in tissue is a non-equilibrium process.

The surface of bio-membranes and filaments such as collagen fibres can act as biomolecular templates and direct a linear or 2- and 3-dimensional alignment (non- globular growth) of gold nanoparticle leading to the formation of above reported mesostructures, as seen in the tattoo of the lady skin after flush over and evaporation of her neck ornamental chain. When colloidal nanoparticles are deposited from solution on to a substrate, a wide variety of spontaneous nonequilibrium patterns can form. These include self-organized structures such as isolated islands and wormlike domains, continuous labyrinthine and network structures, viscous fingering-like fractal structures, and micrometer-sized rings. Both nucleation and growth and spinodal mechanisms are responsible for many of these structures [31]. In contrast to usual crystals, which are formed by three-dimensional, strictly ordered periodical arrangement of atoms, these structures (mesocrystals) are formed by highly parallel crystallisation and controlled alignment of nanoparticle units [32].

The biodegradation of gold as well as of titanium and platinum tissue has been investigated by implanting gold grids and middle ear prosthesis in rats and humans. Markedly dissolution of the pure gold and recrystallization of gold in the neighbourhood of implants has been observed. Titanium and platinum resisted better the biodegadation than gold. Dissolved gold re-precipitated in form of round-shaped lessordered nanoparticles. The repeated dissolution-precipitation process led to a migration of gold into the fare off tissue and was connected with the inflammation and fibrosis of the corresponding tissue. The repeated dissolution and recrystallization process of gold nanoparticle is also connected with the formation of highly-ordered crystalline and wellshaped decahedral and icosahedral gold nanocrystals. They are thermodynamic favoured because they are most stable forms of nanoparticles at the "end stage".

It is proposed that biodegradation of gold and other recalcitrant metal implants in tissue is mainly due to enzymes like myeloperoxidase inside lysosomes of inflammatory cells, which produce hypochloride ions and hydrogen peroxide 
$\mathrm{H}_{2} \mathrm{O}_{2}$ which can dissolve the gold. Indeed, the tissue provides all necessary conditions for the biodegradation of less pure or shaped pure gold micro tools. This explains also the different shape of re-crystallized gold particles in the connective tissue, round or ellipsoid shaped and more complex structures in the cells.

The observed stronger biodegradation of gold implants led recently to a scarce implantation of gold middle ear prostheses and other filigree implants for long-term administration in patients (personal communication, U. Vick, T. Just). The clinical evaluation of different metallic middle ear prostheses was given by Vick, et al. [33-36].

\section{Acknowledgement}

We are thankful to Ute Schulz of the Electron Microscopic Centre Rostock for their excellent technical assistance.

\section{Highlights}

- The stability of noble $\mathrm{Au}$ and Pt implants in rats and humans has been investigated

- The Au undergoes markedly biodegradation as shown by TEM leading to a decreased durability of Au implants and side effects as inflammation and fibrosing

- Gold re-crystallizes as nanoparticles in the neighborhood of the implant forming nanoparticles of different size and shape

- During re-dissolution-re-crystallization Au anoparticles migrate into the tissue and form high crystalline decahedral and icosahedral particles

- Dissolution of gold is attributed to oxidative attack by reactive oxygen species

\section{References}

1. Jonas L, Fulda G, Nizze H, Zimmermann R, Gross G, et al. Detection of gold particles in the neck skin after lightning stroke with evaporation of an ornamental chain. Ultrastr Pathol. 2002; 26: 153-159.

PubMed: https://www.ncbi.nlm.nih.gov/pubmed/12184373

2. Laing $P G$, Ferguson $A B$, Hodge $E S$. Tissue reaction in rabbit muscule exposed to metallic implants. J Biomed Mater Res. 1967; 1: 135-149. PubMed: https://www.ncbi.nlm.nih.gov/pubmed/5605609

3. Lalor PA, Revell PA, Gray AB, Wright $S$, Railton $G T$, et al. Sensitivity to titanium. A cause of implant failure? J Bone Joint Surg. 1991; 73: 2528. PubMed: https://www.ncbi.nlm.nih.gov/pubmed/1991768

4. Meachim G, Williams DF. Changes in nonosseous tissue adjacent to titanium implants. J Biomed Mater Res. 1973; 7: 555-572.

PubMed: https://www.ncbi.nlm.nih.gov/pubmed/4589049

5. Moberg LE, Nordenram A, Kjellman O. Metal release from plates used in jaw fracture treatment. A pilot study. Int J Oral Maxiofac Surg. 1989; 18: 311-314.

PubMed: https://www.ncbi.nlm.nih.gov/pubmed/2509588

6. Rosenberg K, Gratz W, Sailer HF. Should titanium miniplates be removed after bone healing is complete? Int J Oral Maxiofac Surg. 1993; 22: 185-188.

PubMed: https://www.ncbi.nlm.nih.gov/pubmed/8340633
7. Schliephake H, Reiss G, Urban R, Neukam FW, Guckel S. Metal release from titanium fixtures during placement in the mandible. An experimental study. Int J Oral Maxiofac Implants. 1993; 8: 502-511. PubMed: https://www.ncbi.nlm.nih.gov/pubmed/8112789

8. Schliephake $H$, Lehmann $H$, Kunz U, Schmelzeisen R. Ultrastructural findings in soft tissue adjacent to titanium plates used in jaw fracture treatment. Int J Oral Maxiofac Surg. 1993; 22: 20-25.

PubMed: https://www.ncbi.nlm.nih.gov/pubmed/8459118

9. J Black. Does corrosion matter? J Bone Joint Surg. 1988; 708: 517520. PubMed: https://www.ncbi.nlm.nih.gov/pubmed/3403590

10. Besssho K, Fujimura K, lizuka T. Experimental long-term study of titanium ions eluted from pure titanium miniplates. J Biomed Mater Res. 1995; 31: 901-904.

PubMed: https://www.ncbi.nlm.nih.gov/pubmed/7593030

11. Lesniewicz, Gackiewcz L, Zyrnicki W. Biodegradation of metallic surgical implants investigated using an ultrasound-assisted process combined with ICP-OES and XRD. Int Biodeter Biodegr. 2010; 64: 81-85.

12. Jorgenson DS, Centeno JA, Mayer MH, Topperm MJ, Nossov PC, et al. Biologic response to passive dissolution of titanium craniofacial microplates. Biomaterials. 1999; 20: 675-682.

PubMed: https://www.ncbi.nlm.nih.gov/pubmed/10208410

13. Jonas L, Fulda G, Radeck C, Henkel KO, Holzhüter G, et al. Biodegradation of titanium implants after long-time insertion used fort he treatment of fractured upper and lower jaws through osteosynthesis, Elemental analysis by electron microscopy and EDX or EELS. Ultrastr Pathol. $2001 ; 25$ : 375-383.

14. Wang JC, Yu WD, Sandhu HS, Betts F, Bhuta S, et al. Metal debris from titanium spinal implants. Spine. 1999; 24: 899-903.

PubMed: https://www.ncbi.nlm.nih.gov/pubmed/10327512

15. Kaufmann T, Bloch C, Schmidt W, Jonas L. Chronic inflammation and pain inside the mandibular jaw and a 10-year forgotten amalgam filling in an alveolar cavity of an extracted molar tooth. Ultrastr Pathol. 2005; 29: 405-413.

PubMed: https://www.ncbi.nlm.nih.gov/pubmed/16257867

16. Jonas L, Bloch C, Zimmermann R, Stadie V, Gross GE, et al. Detection of silver sulfide deposits in the skin of patients with argyria after longterm use of silver-containing drugs. Ultrastr Pathol. 2007; 31: 379-384. PubMed: https://www.ncbi.nlm.nih.gov/pubmed/18098055

17. Danscher G. In vivo liberation of gold ions from gold implants. Autometallographic tracing of gold in cells adjacent to metallic gold. Histochem. Cell Biol. 2002; 117: 447-452.

PubMed: https://www.ncbi.nlm.nih.gov/pubmed/12029492

18. Bond GC, Louis C, Thompson DT. Catalysis by Gold.

19. Hutchings GJ. Imperial College Press, Catalytic Science Series, London. 2006.

20. St. Nolan P. Organic Chemistry: Catalytic gold rush. Nature. 2007; 445: 496-497.

PubMed: https://www.ncbi.nlm.nih.gov/pubmed/17268459

21. Addison CC, Brownlee GS, Logan N. Tetranitratoaurates(III): preparation, spectra, and properties. J Chem Soc. 1972; 14: 14401445.

22. Büchner O, Wickleder MS. $\left(\mathrm{NO}_{2}\right)\left\{\mathrm{Au}\left(\mathrm{NO}_{3}\right)_{4}\right]$ : Synthese, Struktur und thermischer. Anorg Allg Chem. 2004; 630: 1714.

23. Kozin LF, Prokopenko VA, Bogdanova AK. Kinetics and Mechanism of the gold corrosion dissolution in hypochlorite solution. Protection of Metals. 2005; 41: 22-29. 
24. Gusmano G, Montanari R, Kaciulis S, Montesperelli G, Denk R. Gold corrosion: red strains on a gold austrian ducat. Appl Phys A. 2004; 79: 205-211.

25. Mineev GG, Panchenko AF. Rastvoriteli zolota i serebra v gidrometallurgii (Solvents for Gold and Silver in Hydrometallurgy), Moscow. Metallurgy. 1994.

26. Cao Zh, Zhong-Liang X, Gu N, Fu-Chun G, Dao-Wu Y, et al. Corrosion behaviors on polycrystalline gold substrates in self-assembled processes of alkanethiol monolayers. Anal Lett. 2005; 38: 1289-1304.

27. Turkevich J, Stevenson PC, Hillier J. A study of the nucleation and growth processes in the synthesis of colloidal gold. Discuss Faraday Soc. $1951 ; 11: 55-75$.

28. Lu W, Wang W, Su Y, Li J, Jiang L. Formation of polydiacetylene$\mathrm{NH} 2$-gold hollow spheres and their ability in DNA immobilization Nanotechnology. 2005; 16: 2582-2586.

29. Zhang X, Li D. Metal-compound induced vesicles as efficient directors for rapid synthesis of hollow alloy spheres. Angew Chem Int Ed. 2006; 45: 5971-5974.

PubMed: https://www.ncbi.nlm.nih.gov/pubmed/16897809

30. Meldrum FC, Colfen $\mathrm{H}$. Controlling mineral morphologies and structure in biological and synthetic systems. Chem Rev. 2008; 108: 4332-4432. PubMed: https://www.ncbi.nlm.nih.gov/pubmed/19006397
31. Brutchey RL, Morse DE. Silicatein and the translation of its molecular mechanism of biosilification into low temperature nanomaterial synthesis. Chem Rev. 2008; 108: 4915-4934.

PubMed: https://www.ncbi.nlm.nih.gov/pubmed/18771329

32. Stannard C, Martin P, Pauliac-Vaujour E, Moriarty P, Vancea I, et al. Controlling Pattern Formation in Nanoparticle Assemblies via Directed Solvent Dewetting. J Phys Chem C. 2008; 112: 15195-15203.

PubMed: https://www.ncbi.nlm.nih.gov/pubmed/17930453

33. Wang $\mathrm{T}, \mathrm{Xu}$ AW, Colfen $\mathrm{H}$. Formation of Self-Organized Dynamic Structure Patterns of Barium Carbonate Crystals in Polymer-Controlled Crystallization. Angew Chem Int Ed. 2006; 45: 4451-4455.

PubMed: https://www.ncbi.nlm.nih.gov/pubmed/16789037

34. Cölfen H, Antonietti M. Mesokristalle: anorganische Überstrukturen durch hochparallele Kristallisation und kontrollierte Ausrichtung. Angew Chem. 2005; 117: 5714-5730.

35. Vick U, Just T, Pau HW. Fulda G, Laabs W, Jonas L. Experimentelle Biodegradation von Titanimplantaten in der Mittelohrchrirurgie. Biomaterialien. 2005; 6: 86-87.

36. Vick U, Just T, Ostwald J, Pau HW, Jonas L. Experimentelle und klinische Untersuchungen zur Biodegradation von Mittelohrimplantaten und ihr Einfluß auf das Langzeithörvermögen. Biomaterialien. 2005; 6: 60-61. 